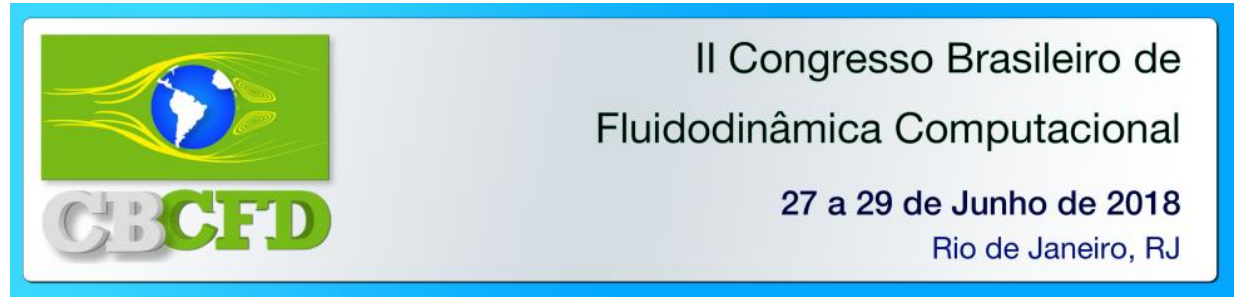

\title{
SIMULAÇÃO DO EMPACOTAMENTO DE MISTURAS BINÁRIAS DE ESFERAS DE VIDRO EMPREGANDO O MÉTODO DE ELEMENTOS DISCRETOS
}

\author{
D. B. FERREIRA ${ }^{1}$, D.L. SOUZA ${ }^{1}$, J.L. VIEIRA NETO ${ }^{1}$, K..G. SANTOS ${ }^{1 *}$ \\ ${ }^{1}$ Universidade Federal Do Triângulo Mineiro, Departamento de Engenharia Química \\ *E-mail para contato: kassia.santos@uftm.edu.br
}

\begin{abstract}
RESUMO - O leito de jorro é um equipamento altamente influenciado pela porosidade do leito estático. Assim, este trabalho teve o objetivo de empregar o método de elementos discretos na simulação do empacotamento de partículas de 1 e $4 \mathrm{~mm}$ e de misturas binárias dessas partículas. Foi realizada a calibração dos parâmetros do modelo de força de contato de Hertz-Mindlin. Os resultados mostraram que o coeficiente de atrito estático partícula-partícula é a variável que mais influencia a operação de empacotamento, seguido pelo coeficiente de atrito de rolamento partícula-partícula, enquanto o coeficiente de atrito de rolamento partícula-parede não influenciou a porosidade do leito. As simulações representaram adequadamente a transição entre os regimes de ocupação e enchimento que regem o empacotamento.
\end{abstract}

\section{INTRODUÇÃ̃O}

O Método de Elementos Discretos (DEM), desenvolvido por Cundall e Strack (1979), é uma boa alternativa para modelagem de sistemas particulados densos, pois contabiliza o efeito do tamanho e forma da partícula, além de permitir detalhamento das colisões presentes.

O leito de jorro é um equipamento altamente influenciado pela porosidade do leito estático. Leitos mais empacotados oferecem maior resistência ao escoamento de partículas, logo, chegam a maiores picos de queda de pressão na curva característica. Neste sentido, o conhecimento do comportamento fluidodinâmico de uma mistura de partículas no leito de jorro é fundamental para o projeto de reatores de pirólise, que devem operar numa condição em que ocorra a mistura de partículas. Assim, o conhecimento da porosidade se torna uma condição inicial essencial para a modelagem e simulação do leito de jorro (SANTOS, 2011).

O empacotamento de misturas binárias de partículas é influenciado por dois mecanismos, que influenciam diretamente na porosidade da mistura, sendo estes o mecanismo de preenchimento e o mecanismo de ocupação (YU e STANDISH, 1991). A porosidade de um leito não está somente relacionada à composição das misturas binárias, mas também às forças de fricção a que as partículas são submetidas e ao método de empacotamento.

Há dois mecanismos que influenciam diretamente na porosidade da mistura. $O$ mecanismo de enchimento ocorre quando a estrutura ou esqueleto formado pelas partículas maiores não se altera devido à adição de outras partículas menores (Fig. 1a). Para maiores razões de tamanho entre as partículas, ocorre o mecanismo de ocupação, no qual ambos os componentes influenciam a estrutura de empacotamento e consequentemente a porosidade da mistura no leito (Fig. 1b).

A Figura 1c mostra dois leitos formados por partículas de esfericidade diferente, que poderia representar o que acontece com a mistura de partículas no processo da pirólise, em 


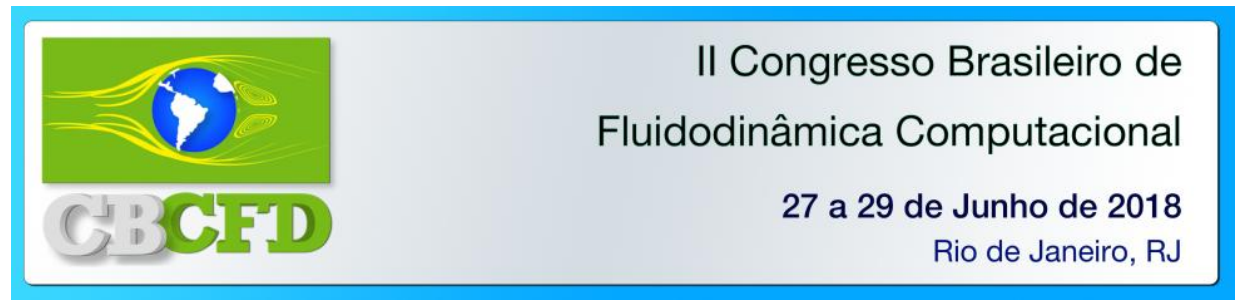

que têm-se a areia, de formato mais regular, e biomassas fibrosas como o bagaço de cana, sorgo e bagaço de malte.

Assim, o presente trabalho teve o objetivo de investigar o efeito do coeficiente de atrito estático e de rolamento partícula-partícula e partícula-parede sobre a porosidade do leito após o empacotamento livre de esferas de vidro de $4 \mathrm{~mm}$. Os valores de coeficientes selecionados foram empregados na simulação da condição de empacotamento máximo, no qual a porosidade do leito com mistura binária de partículas é mínima.

Figura 1 - Mecanismos de empacotamento, em que as linhas pontilhadas representam as ligações entre o componente que controla a mistura: (a) de enchimento; (b) de ocupação; (c) mistura de partículas não esféricas, em que predomina o mecanismo de enchimento.

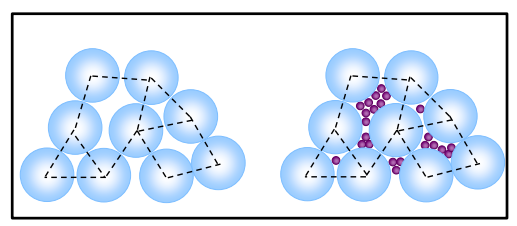

(a)

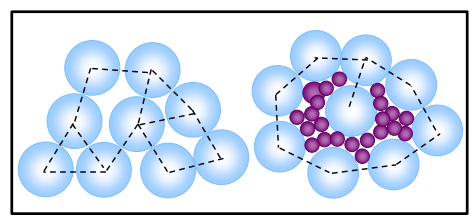

(b)

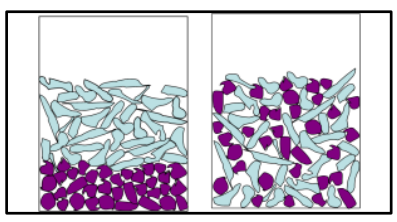

(c)

\section{MÉTODO}

A metodologia DEM e suas variantes estão bem estabelecidas e são descritas em detalhes por Cleary (2008). O modelo de contato, usado para contabilizar as forças de interação entre duas esferas rígidas que pertencem a duas diferentes partículas, é baseado no modelo de Hertz-Mindlin, que caracteriza as interações por meio de três coeficientes: coeficiente de restituição, coeficiente de atrito estático e coeficiente de atrito de rolamento. Neste trabalho, empregou-se um coeficiente de restituição de 0,9 e a Razão de Poison de 0,25, enquanto que os coeficientes de atrito estático e de rolamento partícula-partícula (PP) e partícula-parede (PW) foram calibrados comparando os melhores valores simulados (de acordo com a Tabela 1) com o valor experimental para o sistema de empacotamento de esferas de vidro de $4 \mathrm{~mm}$.

O software EDEM foi empregado para a realização das simulações de empacotamento de partículas. Foram empregadas partículas de esferas de vidro de 1 e $4 \mathrm{~mm}$ de diâmetro, e com massa específica de $2480 \mathrm{~kg} / \mathrm{m}^{3}$, de acordo com Santos (2011). A geometria do cone foi construída conforme a do leito de jorro, com diâmetro de base de $0,035 \mathrm{~m}$, altura de $0,15 \mathrm{~m}$ e abertura final de $0,21 \mathrm{~m}$ de diâmetro.

Nas simulações do empacotamento de partículas, um plano de injeção foi criado para viabilizar a adição das partículas ao leito até que não houvesse mais volume disponível para a inserção de novas partículas. Ao fim da simulação, o número de partículas que compunham o leito era coletado e calculado o fator de empacotamento e a porosidade do leito. Após a calibração, foi realizada a simulação da mistura binária correspondente à mínima porosidade e comparada com os dados experimentais e o modelo algébrico de Dias et al. (2004).

\section{RESULTADOS E DISCUSSÕES}

O Planejamento Composto Central com 27 análises do empacotamento de esferas de vidro de $4 \mathrm{~mm}$ apresentou variação no número de partículas e consequentemente na porosidade (Tabela 1). Santos (2011) descreve que o leito empacotado com esferas de vidro de $4 \mathrm{~mm}$ apresenta porosidade de 0,409. Este resultado foi obtido de maneira aproximada na 


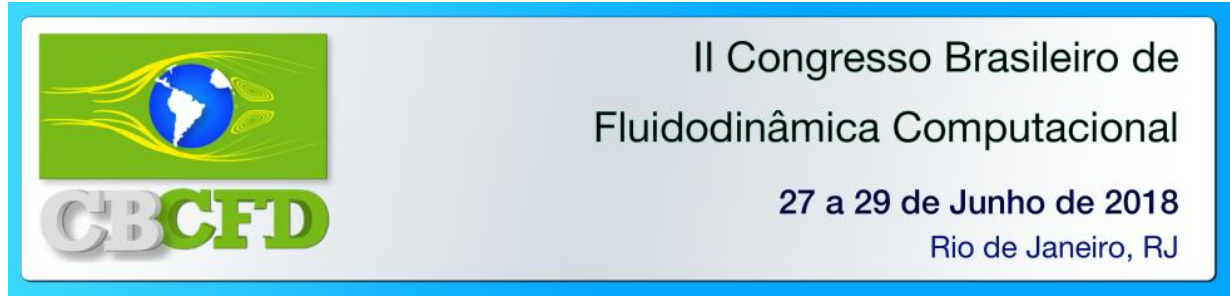

condição de número 18 do planejamento $\left(\mu_{s-P P} 0,964 ; \quad \mu_{r-P P}=0,200 ; \quad \mu_{s-P W}=0,200\right.$; $\left.\mu_{r-P W}=0,100\right)$, que apresenta alto valor de coeficiente de atrito estático partícula-partícula $(0,964)$ e as outras variáveis no nível intermediário.

Tabela 1 - Planejamento Composto Central para avaliação dos parâmetros e resultados de porosidade.

\begin{tabular}{|c|c|c|c|c|c|c|}
\hline Simulação & $\begin{array}{c}\mathrm{X}_{1} \\
\left(\mu_{s-P P}\right)\end{array}$ & $\begin{array}{c}\mathrm{X}_{2} \\
\left(\mu_{r-P P}\right)\end{array}$ & $\begin{array}{c}\mathrm{X}_{3} \\
\left(\mu_{s-P W}\right)\end{array}$ & $\begin{array}{c}\mathrm{X}_{4} \\
\left(\mu_{r-P W}\right)\end{array}$ & $\varepsilon_{D E M}$ & $\begin{array}{c}\sigma \\
{[\%]}\end{array}$ \\
\hline 1 & $-1,000(0,200)$ & $-1,000(0,100)$ & $-1,000(0,200)$ & $-1,000(0,040)$ & 0,368 & $-11,280$ \\
\hline 2 & $-1,000(0,200)$ & $-1,000(0,100)$ & $-1,000(0,200)$ & $+1,000(0,160)$ & 0,371 & $-10,099$ \\
\hline 3 & $-1,000(0,200)$ & $-1,000(0,100)$ & $+1,000(0,800)$ & $-1,000(0,040)$ & 0,372 & $-9,945$ \\
\hline 4 & $-1,000(0,200)$ & $-1,000(0,100)$ & $+1,000(0,800)$ & $+1,000(0,160)$ & 0,373 & $-9,507$ \\
\hline 5 & $-1,000(0,200)$ & $+1,000(0,300)$ & $-1,000(0,200)$ & $-1,000(0,040)$ & 0,373 & $-9,703$ \\
\hline 6 & $-1,000(0,200)$ & $+1,000(0,300)$ & $-1,000(0,200)$ & $+1,000(0,160)$ & 0,373 & $-9,594$ \\
\hline 7 & $-1,000(0,200)$ & $+1,000(0,300)$ & $+1,000(0,800)$ & $-1,000(0,040)$ & 0,376 & $-8,856$ \\
\hline 8 & $-1,000(0,200)$ & $+1,000(0,300)$ & $+1,000(0,800)$ & $+1,000(0,160)$ & 0,377 & $-8,556$ \\
\hline 9 & $-1,000(0,200)$ & $-1,000(0,100)$ & $-1,000(0,200)$ & $-1,000(0,040)$ & 0,391 & $-4,631$ \\
\hline 10 & $+1,000(0,800)$ & $-1,000(0,100)$ & $-1,000(0,200)$ & $+1,000(0,160)$ & 0,392 & $-4,393$ \\
\hline 11 & $+1,000(0,800)$ & $-1,000(0,100)$ & $+1,000(0,800)$ & $-1,000(0,040)$ & 0,393 & $-4,057$ \\
\hline 12 & $+1,000(0,800)$ & $-1,000(0,100)$ & $+1,000(0,800)$ & $+1,000(0,160)$ & 0,396 & $-3,411$ \\
\hline 13 & $+1,000(0,800)$ & $+1,000(0,300)$ & $-1,000(0,200)$ & $-1,000(0,040)$ & 0,423 & 3,351 \\
\hline 14 & $+1,000(0,800)$ & $+1,000(0,300)$ & $-1,000(0,200)$ & $+1,000(0,160)$ & 0,424 & 3,588 \\
\hline 15 & $+1,000(0,800)$ & $+1,000(0,300)$ & $+1,000(0,800)$ & $-1,000(0,040)$ & 0,428 & 4,409 \\
\hline 16 & $+1,000(0,800)$ & $+1,000(0,300)$ & $+1,000(0,800)$ & $+1,000(0,160)$ & 0,426 & 3,958 \\
\hline 17 & $-1,547(0,036)$ & $0,000(0,200)$ & $0,000(0,200)$ & $0,000(0,100)$ & 0,345 & $-18,472$ \\
\hline 18 & $+1,547(0,964)$ & $0,000(0,200)$ & $0,000(0,200)$ & $0,000(0,100)$ & 0,410 & 0,265 \\
\hline 19 & $0,000(0,500)$ & $-1,547(0,045)$ & $0,000(0,200)$ & $0,000(0,100)$ & 0,379 & $-7,959$ \\
\hline 20 & $0,000(0,500)$ & $+1,547(0,355)$ & $0,000(0,200)$ & $0,000(0,100)$ & 0,419 & 2,442 \\
\hline 21 & $0,000(0,500)$ & $0,000(0,200)$ & $-1,547(0,036)$ & $0,000(0,100)$ & 0,399 & $-2,448$ \\
\hline 22 & $0,000(0,500)$ & $0,000(0,200)$ & $+1,547(0,964)$ & $0,000(0,100)$ & 0,405 & $-1,054$ \\
\hline 23 & $0,000(0,500)$ & $0,000(0,200)$ & $0,000(0,200)$ & $-1,547(0,007)$ & 0,402 & $-1,765$ \\
\hline 24 & $0,000(0,500)$ & $0,000(0,200)$ & $0,000(0,200)$ & $+1,547(0,193)$ & 0,398 & $-2,716$ \\
\hline 25 & $0,000(0,500)$ & $0,000(0,200)$ & $0,000(0,200)$ & $0,000(0,100)$ & 0,402 & $-1,709$ \\
\hline 26 & $0,000(0,500)$ & $0,000(0,200)$ & $0,000(0,200)$ & $0,000(0,100)$ & 0,403 & $-1,427$ \\
\hline 27 & $0,000(0,500)$ & $0,000(0,200)$ & $0,000(0,200)$ & $0,000(0,100)$ & 0,401 & $-1,954$ \\
\hline
\end{tabular}

Quanto a análise do efeito das variáveis sobre o empacotamento, observa-se por meio da Equação $1\left(\mathrm{R}^{2}=0,9885\right)$ e da superfície de resposta (Fig. 2), que o coeficiente de atrito estático partícula-partícula é a variável que mais influencia a operação de empacotamento, seguida pelo coeficiente de atrito de rolamento partícula-partícula e a interação entre eles. Nas simulações realizadas, o coeficiente de atrito de rolamento entre partícula-parede não influenciou o valor da porosidade do leito.

Após as simulações do leito com monopartículas, realizou-se a simulação correspondente à condição de mínima porosidade, que representa a transição entre os mecanismos de enchimento e ocupação. Para tal, utilizou-se a condição de empacotamento das partículas de $4 \mathrm{~mm}$ e foram adicionadas as partículas de $1 \mathrm{~mm}$ até o preenchimento total dos espaços vazios entre as partículas grandes. 


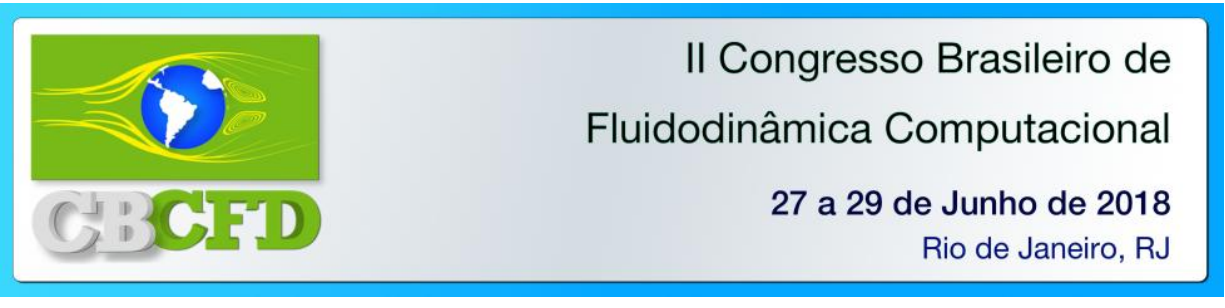

A Figura 3 mostra a comparação da porosidade obtida para as misturas de 1 e $4 \mathrm{~mm}$ obtidas experimentalmente, pelo modelo de Dias et al. (2004) e pela simulação DEM. Infelizmente, os métodos de injeção de partículas testados não foram eficientes quando se trabalhou no regime de ocupação. Além disso, não foi possível realizar as simulações das outras misturas de areia e biomassas, devido ao altíssimo custo computacional das simulações empregando partículas de $1 \mathrm{~mm}$, que chegaram a semanas.

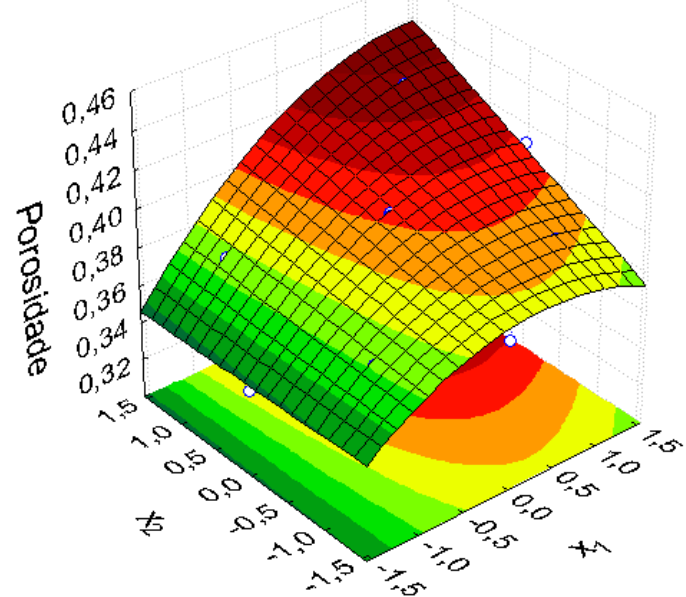

Figura 2 - Porosidade do leito $(\mathrm{dp}=4 \mathrm{~mm})$ em função de $\mathrm{x}_{1}\left(\mu_{s-P P}\right)$ e $\mathrm{x}_{2}\left(\mu_{r-P P}\right)$.

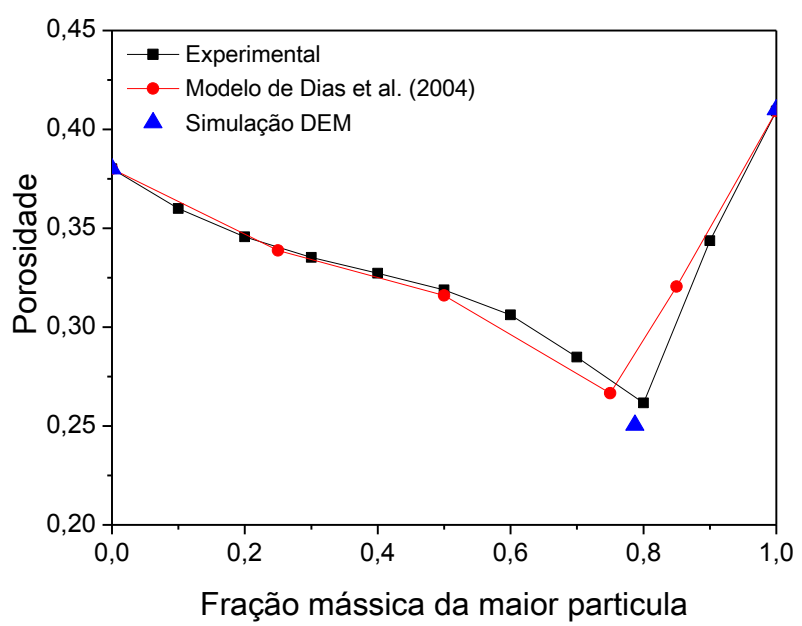

Figura 3 - Mistura binária de partículas esféricas de 1 e $4 \mathrm{~mm}$ : dados experimentais de Santos (2011), modelo de Dias et al. (2004) e simulações DEM.

\section{CONCLUSÃO}

As simulações DEM se mostraram capazes de representar o empacotamento de sistemas monopartículas e de misturas de partículas. O coeficiente de atrito estático partículapartícula é o fator que mais influencia a porosidade do leito e, portanto, seria adequado calculá-lo de forma experimentalmente precisa. Em misturas muito ricas em esferas de vidro de $1 \mathrm{~mm}$, em que predomina o mecanismo de ocupação, a geração conjunta das partículas de 1 e $4 \mathrm{~mm}$ é dificultada, uma vez que as partículas maiores caem antes das menores, gerando segregação. Assim, outros métodos de geração de partículas devem ser estudados.

\section{REFERENCIAS}

CLEARY, P.W. The effect of particle shape on simple shear flows. Powder Technology, v.179, p.144163, 2008.

CUNDALL, P. A.; STRACK, O. D. L. A discret numerical model for granular assemblies. Geotech., v. 29, p. 47-65, 1979.

DIAS, R. P.; TEIXEIRA, J. A.; MOTA, M. G. e YELSHIN, A. I. Particulate Binary Mixtures: Dependence of Packing Porosity on Particle Size Ratio, Industrial Engineering Chemistry Research, v.43, p. 7912-7919, 2004.

SANTOS, K. G. Aspectos fundamentais da pirólise de biomassa em leito de jorro: Cinética e fluidodinâmica do processo, Tese de doutorado, FEQUI-UFU, Uberlândia-MG, 235p., 2011.

YU, A. B.; STANDISH, N. Estimation of the porosity of particle mixtures by a linear-mixture packing model, Industrial Engineering Chemistry Research, v. 30 (6), p. 1372-1385,1991.

\section{AGRADECIMENTOS}

Os autores agradecem o suporte da Capes (AUXPE0856/2015) e Fapemig (PPM-00564-16). 